\title{
Stimulation of plant growth and biocontrol by Bacillus amyloliquefaciens subsp. plantarum FZB42 engineered for improved action
}

\author{
Jun-Qing Qiao ${ }^{1,2}$, Hui-Jun Wu1 ${ }^{1}$, Rong Huo ${ }^{1}$, Xue-Wen Gao ${ }^{1 *}$ and Rainer Borriss $3,4^{*}$
}

\begin{abstract}
During the last decade, the use of plant-root colonizing bacteria with plant growth-promoting activity has been proven as an efficient and environmental-friendly alternative to chemical pesticides and fertilizers. Biofertilizer and biocontrol formulations prepared from endospore-forming Bacillus strains are increasingly applied due to their long shelf life, which is comparable with that of agrochemicals. Today, spore suspensions from natural representatives of mainly Bacillus amyloliquefaciens, Bacillus subtilis, and Bacillus pumilus are available. However, these biofertilizers, directly prepared from environmental strains, are sometimes hampered in their action and do not fulfill in each case the expectations of the appliers (Borriss R, Bacteria in agrobiology: plant growth responses, Springer, 2011, pp. 41-76). This review will focus on several ways to improve the action of $B$. amyloliquefaciens subsp. plantarum $\mathrm{FZB} \mathrm{2}^{\top}$, the type strain for the group of plant-associated B. amyloliquefaciens strains. We are focusing here on genomics and genetic engineering techniques as helpful tools for developing more powerful biofertilizer and biocontrol agents.
\end{abstract}

Keywords: Plant growth promotion; Bacillus amyloliquefaciens subsp. plantarum; Biofertilizer; Biocontrol; Harpin genes

\section{Introduction}

In recent years, use of biologicals in plant protection is steadily increasing and begins to replace, in part, chemical pesticides. An increasing number of farmers are recognizing the need for other avenues for pest control that are not as damaging to the environment and the land. Henceforth, they are turning to biopesticides to prevent pest damage in a more ecological-friendly manner that includes targeted applications, lower residues, and fewer applications. According to a comprehensive study of BCC Research, global markets for biopesticides will grow from US\$54.8 billion in 2013 to US\$61.8 billion in 2014 . This is estimated to reach US $\$ 83.7$ billion by 2019 , with a 5-year compound annual growth rate (CAGR) of $6.3 \%$ from 2014 through 2019 (http://www.bccresearch.com/ market-research/chemicals/biopesticides-chm029e.html). Thereby, biological preparations from spore-forming

\footnotetext{
* Correspondence: gaoxw@njau.edu.cn; rainer.borriss@rz.hu-berlin.de ${ }^{1}$ College of Plant Protection, Nanjing Agricultural University, Key Laboratory of Monitoring and Management of Crop Disease and Pest Insects, Ministry of Agriculture, Nanjing 210095, China

${ }^{3}$ Institute of Biology/Bacterial Genetics, Humboldt University, Berlin, Germany Full list of author information is available at the end of the article
}

Bacillus spp. are preferred, because their long-term viability facilitates the development of commercial products. Unfortunately, their success in agricultural application is still hampered by insufficient knowledge about basic mechanisms of interactions between bacilli and plants, although some progress has been made in last decade [1].

Plant-associated Bacillus amyloliquefaciens strains belonging to subsp. plantarum [2] are distinguished from other representatives of endospore-forming B. amyloliquefaciens by their ability to colonize plant rhizosphere, to stimulate plant growth, and to suppress competing phytopathogenic bacteria and fungi. Due to their biofertilizer and biocontrol properties, they are becoming increasingly important as a natural alternative to chemical pesticides and other agrochemicals. We have focused our research on $B$. amyloliquefaciens $\mathrm{FZB}_{2} 2^{\mathrm{T}}$ [3], the type strain for B. amyloliquefaciens subsp. plantarum. Comparative genome analysis, transposon mutagenesis, and transcriptome and proteome analysis of this model organism are valuable means to evaluate its plant growthpromoting activity. A network of research activities was established in frame of national and international 
programs to elucidate the interaction of the beneficial bacterium with plants, plant pathogens, and the microbial community living on plant roots. The outcome of this research will contribute to the development of an efficient and environmental-friendly plant protection agent. In order to reveal the specific genomic features linked with the properties beneficial for plant growth and biocontrol, we have sequenced the whole genome of FZB42 as the first example of gram-positive plant beneficial bacteria [4].

\section{Review}

\section{Rhizosphere bacilli}

Land plants and bacteria have shared the same environment for approximately 360 to 480 million years [5]. The contact between them has developed into various dependencies on both sides. Plants and certain rhizobacteria form mutually beneficial associations mediated through an exchange of chemical metabolites [1].

Plant growth-promoting Bacilli, like FZB42, are able to propagate in the rhizosphere, the soil environment influenced by plant roots. This environment is highly competitive due to the nutrient-rich rhizodeposits consisting of a wide variety of compounds derived from sloughed off root cells and tissues, mucilages, and soluble exudates originating from intact roots [6]. However, roots respond to signals that stimulate defense responses (salicylic and jasmonic acids) by exuding a range of secondary metabolites, such as saponins, glucosinolates, hydroxamic acids, and naphthoquinones, which are inhibiting the growth of many 'ordinary' (not adapted to plant colonization) bacteria or fungi in this area.

The ability of FZB42 to colonize the rhizoplane is a precondition for plant growth promotion [7]. Using a GFPtagged derivative [8], the fate of bacterial root colonization was recently studied. It ruled out that the bacterium behaves distinctly in colonizing root surfaces of different plants. In contrast to maize, FZB42 colonized preferentially root tips when colonizing Arabidopsis thaliana [9]. On duckweed, Lemna minor, FZB42 accumulated preferably along the grooves between epidermal cells of roots and in the concave spaces on ventral sides of fronds. In vitro studies performed with maize seedlings revealed that the segment within 2 to $8 \mathrm{~cm}$ distance from the basal site of the primary root was the most colonized region by FZB42. On the contrary, few bacterial cells could be observed within the range of $2 \mathrm{~cm}$ of root tip. In general, the green fluorescent FZB42 were decreasingly observed from the upper part of a root down to the root tip. Scanning electron microscopy confirmed the presence of FZB42 on root hairs, where the bacterial cells were usually associated with a wealth of presumed root exudates [10]. In lettuce (Lactuca sativa) seedlings, bacterial colonization occurred mainly on the primary roots and root hairs, as well as on root tips and adjacent border cells. Occurrence of labelled bacteria decreased towards the root tips of the lateral roots, and no colonization of the finer roots was observed [11].

\section{Genomics and other -omics techniques are useful for dissecting interactions between FZB42 and plants}

The whole genome sequence of the type strain of plant-associated B. amyloliquefaciens subsp. plantarum, FZB $42^{\mathrm{T}}$, has been determined in 2007, as the first representative of gram-positive, plant growth-promoting bacteria. Its 3,918-kb genome, containing an estimated 3,695 protein coding sequences (CDS), lacks extended phage insertions, which occur ubiquitously in the related Bacillus subtilis 168 genome. The $B$. amyloliquefaciens genome reveals a huge potential to produce secondary metabolites, including the polyketides bacillaene, macrolactin, and difficidin. More than $8.5 \%$ of the genome is devoted to synthesizing antibiotics and siderophores by pathways not involving ribosomes [12]. A comparison of its genomic sequence with that of the B. amyloliquefacienstype strain $\mathrm{DSM}^{\mathrm{T}}$ revealed significant differences in the genomic sequences of both strains [13]. The strains have in common 3,345 CDS residing in their core genomes; while 547 and 344 CDS were found to be unique in FZB $42^{\mathrm{T}}$ and $\mathrm{DSM} 7^{\mathrm{T}}$, respectively. Notably, the gene clusters encoding non-ribosomal synthesis of antibacterial polyketides difficidin and macrolactin $[14,15]$ are absent in DSM7 $7^{\mathrm{T}}$. For comparison, B. subtilis $168^{\mathrm{T}}$ has a similar number of CDS in common with $B$. amyloliquefaciens strains $\mathrm{DSM}^{\mathrm{T}}$ and $\mathrm{FZB} 42^{\mathrm{T}}$ (3,222 and 3,182 CDS, respectively). Meanwhile, besides FZB42 ${ }^{\mathrm{T}}$, the genomes of other B. amyloliquefaciens plantarum strains have become available [16]. The core genome formed by 15 B. amyloliquefaciens plantarum genomes includes 3,151 genes, the pan-genome more than 6,000 genes, suggesting a high degree of flexibility in the genomes of such plant-associated B. amyloliquefaciens strains. Nevertheless, as has been shown in a previous study, the genomes of the plantarum subsp. are well distinguished from the non-plant-associated amyloliquefaciens subsp. [2]. In addition, except $\mathrm{DSM}^{\mathrm{T}}$, the genomes of three other representatives of the subsp. amyloliquefaciens have been published, enabling a comparative genome analysis of plant root-associated and free-living soil $B$. amyloliquefaciens strains. Fifty-four genes were identified as being unique for subspecies plantarum and did not occur in the free-living soil bacterium B. amyloliquefaciens subsp. amyloliquefaciens, e.g., gene clusters involved in the synthesis of difficidin and macrolactin and in carbon metabolism (Table 1). Genes involved in ribosomal synthesis of several bacteriocins, such as mersacidin [17], plantazolicin [18], and amylocyclicin [19], were detected in several representatives of $B$. amyloliquefaciens subsp. plantarum but are not part of the plantarum core 
Table 1 Singletons occurring in Bacillus amyloliquefaciens subsp. plantarum (15 genomes), but not in Bacillus amyloliquefaciens subsp. amyloliquefaciens

\begin{tabular}{|c|c|c|c|c|}
\hline Accession number & Description & BS gene & Identity (\%) & Class $^{\mathrm{a}}$ \\
\hline RBAM_001770 & DinB family; cl17821 YizA & BSU10800 & 49 & 6.7 \\
\hline RBAM_002650 & GH25 muramidase YbfG & BSU02200 & 83 & 1.1 \\
\hline RBAM_002660 & Unknown protein & & & 6.7 \\
\hline RBAM_003280 & Alpha-amylase AmyE & BSU03040 & 87 & 2.2 \\
\hline RBAM_003370 & Putative antimicrobial peptide Lci & & & 4.3 \\
\hline RBAM_004550 & 8-oxo-dGTP diphosphatase & BSU04330 & 60 & 3.1 \\
\hline RBAM_004640 & Unknown protein & & & 6.7 \\
\hline RBAM_005260 & Proline/betaine transporter, MFS superfamily & & & 1.2 \\
\hline RBAM_005610 & Cation exporter TrkA, CzcD & BSU26640 & 89 & 1.2 \\
\hline RBAM_005640 & 4-Hydroxy-tetrahydrodipicolinate synthase & NP_389559 & 25 & 2.6 \\
\hline RBAM_006120 & Unknown protein & NP_389102 & 43 & 6.7 \\
\hline RBAM_008480 & Phosphoenolpyruvate synthase, PPDK_N & NP_389764 & 30 & 2.2 \\
\hline RBAM_010040 & DNA alkylation repair enzyme, COG4335 YhaZ & BSU09810 & 63 & 3.1 \\
\hline RBAM_012380 & Uronate isomerase (glucuronate isomerase) UxaC & BSU12300 & 77 & 2.2 \\
\hline RBAM_012390 & Symporter, sugar (glycoside-pentoside-hexuronide) transporter & BSU12310 & 80 & 2.2 \\
\hline RBAM_013540 & Oxidoreductase, NADB_Rossmann & BSU13770 & 97 & 6.6 \\
\hline RBAM_014340 & Macrolactin synthesis; polyketide synthase of type I & & & 4.3 \\
\hline RBAM_014350 & Macrolactin synthesis; polyketide synthase of type I & & & 4.3 \\
\hline RBAM_014360 & Macrolactin synthesis; polyketide synthase of type I & & & 4.3 \\
\hline RBAM_014370 & Macrolactin synthesis; polyketide synthase of type I & & & 4.3 \\
\hline RBAM_014390 & Macrolactin synthesis; polyketide synthase of type I & & & 4.3 \\
\hline RBAM_014400 & Macrolactin synthesis; polyketide synthase of type I & & & 4.3 \\
\hline RBAM_014410 & Macrolactin synthesis; putative penicillin binding protein & & & 4.3 \\
\hline RBAM_017950 & 2-keto-3-deoxygluconokinase KdgK & BSU22110 & 30 & 2.2 \\
\hline RBAM_017960 & Zinc-type alcohol dehydrogenase, Zn_ADH7 YjmD & BSU12330 & 77 & 2.2 \\
\hline RBAM_017970 & 2-keto-3-deoxygluconate-6-phosphate aldolase KdgA & BSU22100 & 41 & 6.2 \\
\hline RBAM_017990 & D-mannonate oxidoreductase, NADB_Rossmann & BSU12350 & 74 & 2.2 \\
\hline RBAM_018000 & Negative transcriptional regulator (Lacl family) KdgR & BSU22120 & 34 & 3.4 \\
\hline RBAM_018100 & Endo-1,4-beta-glucanase, glycoside hydrolase family 5 & BSU18130 & 93 & 2.2 \\
\hline RBAM_018230 & $\mathrm{H}+$ /gluconate symporter and related permeases & BSU40050 & 81 & 3.4 \\
\hline RBAM_019040 & Hypothetical protein, DUF4025 & YP_054581 & 50 & 6.7 \\
\hline RBAM_019290 & Hypothetical protein YoaQ & BSU18700 & 68 & 4.2 \\
\hline RBAM_020240 & Isochorismatase, cystein hydrolase & BSU26760 & 93 & 6.7 \\
\hline RBAM_021810 & Involved in biosynthesis of extracellular polysaccharides & BSU23680 & 65 & 2.2 \\
\hline RBAM_021880 & Metalloprotein with Zn binding site YqjT & BSU23750 & 76 & 6.7 \\
\hline RBAM_021970 & Difficidin synthesis; modular polyketide synthase of type I & & & 4.3 \\
\hline RBAM_021980 & Difficidin synthesis; modular polyketide synthase of type I & & & 4.3 \\
\hline RBAM_021990 & Difficidin synthesis; modular polyketide synthase of type I & & & 4.3 \\
\hline RBAM_022000 & Difficidin synthesis; modular polyketide synthase of type I & & & 4.3 \\
\hline RBAM_022010 & Difficidin synthesis; modular polyketide synthase of type I & & & 4.3 \\
\hline RBAM_022030 & Difficidin synthesis; modular polyketide synthase of type I & & & 4.3 \\
\hline RBAM_022050 & Difficidin synthesis; acyl-CoA synthetase & & & 4.3 \\
\hline RBAM_022060 & Probable acyl carrier protein & & & 4.3 \\
\hline
\end{tabular}




\begin{tabular}{|c|c|c|c|c|}
\hline RBAM_022070 & Difficidin synthesis & & & 4.3 \\
\hline RBAM_022090 & Putative transcription terminator/antiterminator, NGN KOW & BSU01010 & 26 & 3.2 \\
\hline RBAM_026190 & Hypothetical protein YjdF & & & 6.7 \\
\hline RBAM_028450 & Isochorismatase hydrolase, cysteine hydrolase & & & \\
\hline RBAM_030020 & Putative transcriptional regulator (LysR family), HTH_PBP2_LTTR YybE & BSU40670 & 31 & 3.4 \\
\hline RBAM_030030 & Putative acetoacetate decarboxylase & & & \\
\hline RBAM_030040 & Uncharacterized oxidoreductase, ApbA ApbA_C & ykpB & 23 & 6.6 \\
\hline RBAM_033310 & Putative endonuclease $V$, DNA repair enzyme & ywqL & 85 & \\
\hline RBAM_034390 & ABC transporter permease, COG1284 (2xDUF161) & NP_388993 & 30 & \\
\hline RBAM_037270 & Cupin (JmjC) domain protein, cupin 8 & & & \\
\hline RBAM_037280 & ABC transporters with duplicated ATPase UuP & NP_388476 & 33 & \\
\hline RBAM_037810 & Hypothetical protein 2xDUF1529 & & & 6.7 \\
\hline
\end{tabular}

${ }^{a}$ Functional classes: 1.1 cellular processes/cell envelope, 1.2 cellular processes/transporters, 2.2 metabolism/carbon metabolism, 2.6 metabolism/additional metabolic pathways, 3.1 information processing/genetics, 3.2 information processing/RNA synthesis and degradation, 3.4 information processing/regulation of gene expression, 4.2 lifestyles/sporulation, 4.3 lifestyles/coping with stress, 6.2 groups of genes/membrane proteins, 6.6 groups of genes/poorly characterized/ putative enzymes, 6.7 groups of genes/genes of unknown function.

genome. We conclude that most of the genes unique in subsp. plantarum are involved in plant-bacteria interactions. In order to support this idea, we have performed transposon mutagenesis and transcriptome and proteome analysis of FZB42 exposed directly to plants or plant root exudates $[11,20,21]$. Adding of root exudates up to a final concentration of $250 \mathrm{mg}$ dry weight per liter of culture medium was found sufficient to cause a significant response of the FZB42 transcriptome and proteome during transient growth stage. Among the 302 genes with significantly altered expression by root exudates, 189 were annotated with known functions. The transcription of 46 genes involved in carbon and nitrogen utilization was altered in response to root exudates, with 43 of them being upregulated.

A total of 12 genes encoding enzymes involved in the Embden-Meyerhof-Parnas (EMP) pathway (including pgi encoding for glucose-6-phosphate isomerase) and the TCA cycle were significantly upregulated. Nearly a quarter of the genes with altered transcription (46 out of 189) were involved in uptake or utilization of nutrients. This observation corroborated that root exudates serve as energy sources in the interaction between roots and rhizobacteria. A representative selection of genes involved in plant-bacteria interaction is compiled in Table 2.

\section{Plant growth promoting bacilli engineered for enhanced efficiency}

An important feature of plant growth promoting rhizobacteria (PGPRs) is their root colonization activity [22]. After identifying genes involved in root colonization and other plant-bacteria interactions, markerless gene targeting techniques (strains without linked antibiotic resistance marker) are useful techniques in order to generate strains with enhanced rhizosphere competence. Enhanced root colonization and biocontrol activity was gained in $B$. amyloliquefaciens SQR9 by disruption of the global regulator $a b r B$ gene [23]. Other genes, involved in the expression of antimicrobial compounds can also be targeted. The global regulator gene $\operatorname{deg} U$ was shown to control non-ribosomal synthesis of bacillomycin D [25] and bacilysin [26] in FZB42, for example.

Alternatively, reisolating of improved plant growthpromoting strains after being exposed to the natural environment for a distinct time interval, e.g., one vegetation period, is a promising approach [27]. Sequences of the unique restriction modification systems (RM) can serve as a kind of molecular 'barcode', facilitating specific strain identification in the environment. In contrast to Pseudomonas fluorescens and some other gramnegative bacteria, bacilli are known as comparable 'weak' colonizers of plant root surfaces, and plant growthpromoting bacilli are hardly detected later than 3 months after their application [28].

We have developed a specific method to detect FZB42 in environmental samples, previously treated with B. amyloliquefaciens (Rhizovital ${ }^{\circ}$, ABiTEP GmbH, Berlin, Germany), by combining specific methods of enrichment and molecular detection. Five months after its application in field trials, we took soil samples for reisolating FZB42 derivatives. We obtained colonies with the typical morphology of FZB42, after a complex enrichment procedure consisting of the following steps: (1) resuspending of $2.5 \mathrm{-g}$ sample material in $25 \mathrm{ml}$ distilled water under shaking for $2 \mathrm{~h}$, (2) boiling for $1 \mathrm{~h}$, (3) $10 \mathrm{ml}$ of the suspension was added to $40 \mathrm{ml}$ liquid minimal medium with lactose as single carbon source for 1 to 2 days until rod-like bacteria became visible in 
Table 2 Genes involved in plant-bacteria interactions in FZB42

\begin{tabular}{|c|c|c|}
\hline Accession & Gene & Function \\
\hline \multicolumn{3}{|c|}{ Synthesis of IAA (Idris et al. [24]) } \\
\hline RBAM_020800 & $\operatorname{trp} B A$ & Tryptophan synthase subunits A and B, plant growth promotion \\
\hline RBAM_020840 & $\operatorname{trpED}$ & Anthranilate synthase, transferase, plant growth promotion \\
\hline RBAM_035380 & ysnE & Putative IAA acetyl transferase, plant growth promotion \\
\hline \multicolumn{3}{|c|}{ Transposon mutagenesis (Budiharjo et al. [11]) } \\
\hline RBAM_032640 & $\operatorname{deg} U$ & Two-component response regulator, swarming, biofilm formation, root colonization \\
\hline RBAM_030060 & yusV & Putative iron (III) ABC transport ATPase, biofilm formation, root colonization \\
\hline RBAM_035360 & $n f r A$ & NADPH-flavin oxidoreductase, root colonization, plant growth promotion \\
\hline RBAM017410 & & 61 aa protein, plant growth promotion \\
\hline \multicolumn{3}{|c|}{ Transcriptome, enhanced in presence of root exudate (Fan et al. [20]) } \\
\hline RBAM_016150 & flim & Flagellar motor switch protein FliM, motility and chemotaxis \\
\hline RBAM_016190 & flip & Flagellar biosynthetic protein FliP, motility and chemotaxis \\
\hline RBAM_016290 & chec & Chemotaxis protein CheC, motility and chemotaxis \\
\hline RBAM_032580 & $f l g M$ & Negative regulator of flagellin synthesis, motility and chemotaxis \\
\hline RBAM_032510 & hag & Flagellin; involved in elicitation of plant basal defense, motility and chemotaxis \\
\hline RBAM_027680 & luxs & S-ribosylhomocysteine lyase LuxS, biofilm formation \\
\hline RBAM_016860 & $y m c A$ & Control of community development, biofilm formation \\
\hline RBAM_031630 & epsE & Putative exopolysaccharide biosynthesis protein, biofilm formation \\
\hline RBAM_001610 & $\sec Y$ & Preprotein translocase subunit SecY, sec-dependent protein export \\
\hline RBAM_001250 & secE & Preprotein translocase subunit, sec-dependent protein export \\
\hline RBAM_002940 & tatA & sec-independent protein translocase protein TatAD \\
\hline RBAM_002950 & tatC & sec-independent protein translocase protein TatCD \\
\hline RBAM_026150 & phoP & Two-component response regulator, global regulation of the pho regulon \\
\hline RBAM_008360 & glvA & Maltose-6'-phosphate glucosidase GlvA, maltose metabolism \\
\hline RBAM_008380 & glvC & Phosphotransferase system (PTS) maltose-specific enzyme ॥CB \\
\hline RBAM_008370 & $g / v R$ & HTH-type transcriptional regulator GlvR, maltose operon \\
\hline RBAM_035460 & galk & Galactokinase GalK, galactose metabolism \\
\hline RBAM_028430 & pgi & Glucose-6-phosphate isomerase Pgi, carbon core metabolism \\
\hline RBAM_006560 & ydje & Fructokinase homologue YdjE, carbon core metabolism \\
\hline RBAM_026060 & gap B & Glyceraldehyde-3-phosphate dehydrogenase, carbon core metabolism \\
\hline RBAM_031290 & $p g k$ & Phosphoglycerate kinase, carbon core metabolism, gluconeogenesis \\
\hline RBAM_031270 & pgm2 & 2,3-Bisphosphoglycerate-independent phosphoglycerate mutase Pgm \\
\hline RBAM_008330 & acol & Acetoin dehydrogenase E3 (dihydrolipoamide dehydrogenase) AcoL \\
\hline RBAM_014440 & pdhC & Pyruvate dehydrogenase E2 (dihydrolipoamide acetyltransferase) PdhC \\
\hline RBAM_026180 & citZ & Citrate synthase II CitZ, carbon core metabolism, TCA cycle \\
\hline RBAM_017800 & $c i t B$ & Aconitate hydratase CitB, carbon core metabolism, TCA cycle \\
\hline RBAM_019120 & odhB & Succinyltransferase of 2-oxoglutarate dehydrogenase complex \\
\hline RBAM_015920 & sucC & Succinyl-CoA synthetase (beta subunit), carbon core metabolism, TCA \\
\hline RBAM_025500 & $s d h B$ & Succinate dehydrogenase (iron-sulfur protein), carbon core metabolism \\
\hline RBAM_026160 & $m d h$ & Malate dehydrogenase Mdh, carbon core metabolism, TCA cycle \\
\hline RBAM_035770 & licA & PTS lichenan-specific enzyme \|A \\
\hline RBAM_035760 & $\mathrm{licH}$ & 6-Phospho-beta-glucosidase, utilization of lichenan \\
\hline RBAM_036780 & iolA & Methylmalonate-semialdehyde dehydrogenase, utilization of inositol \\
\hline RBAM_036770 & $i o l B$ & Inositol utilization protein B (lolB) \\
\hline
\end{tabular}


Table 2 Genes involved in plant-bacteria interactions in FZB42 (Continued)

\begin{tabular}{|c|c|c|}
\hline RBAM_036760 & io/C & Inositol utilization protein C (lolC) \\
\hline RBAM_036750 & $i o / D$ & Inositol utilization protein D (IolD) \\
\hline RBAM_036740 & iole & Inositol utilization protein E (lolE) \\
\hline RBAM_036730 & iolf & Inositol transport protein lolF \\
\hline RBAM_036720 & $i o / G$ & Myo-inositol 2-dehydrogenase lolG \\
\hline RBAM_036700 & ioll & Inositol utilization protein I (loll) \\
\hline RBAM_036800 & iols & Inositol utilization protein S (IolS) \\
\hline RBAM_006650 & $b d h A$ & Acetoin reductase/butanediol dehydrogenase, synthesis of volatiles \\
\hline RBAM_011430 & oppA & Oligopeptide ABC transporter (binding protein) OppA \\
\hline RBAM_011460 & oppD & Oligopeptide ABC transporter (ATP-binding protein) OppD \\
\hline RBAM_011470 & oppF & Oligopeptide ABC transporter (ATP-binding protein) OppF \\
\hline RBAM_015410 & cys $P$ & Sulfate permease CysP \\
\hline RBAM_016930 & baeE & Malonyl-CoA-[acyl-carrier protein] transacylase (AT) BaeE \\
\hline RBAM_016970 & bael & Enoyl-CoA-hydratase Bael, synthesis of bacillaene \\
\hline RBAM_016990 & bael & Modular polyketide synthase BaeL, synthesis of bacillaene \\
\hline RBAM_017010 & baeN & Hybrid NRPS/PKS BaeN, synthesis of bacillaene \\
\hline RBAM_017020 & baen & Modular polyketide synthase BaeR, synthesis of bacillaene \\
\hline RBAM_022010 & $d f n F$ & Modular polyketide synthase of type I DfnF, synthesis of difficidin \\
\hline RBAM_022000 & $d f n G$ & Modular polyketide synthase of type I DfnG, synthesis of difficidin \\
\hline RBAM_021980 & $d f n l$ & Modular polyketide synthase of type I Dfnl, synthesis of difficidin \\
\hline RBAM_021970 & $d f n J$ & Modular polyketide synthase of type I DfnJ, synthesis of difficidin \\
\hline RBAM_014400 & $\mathrm{m} / \mathrm{nH}$ & Polyketide synthase of type I MlnH, synthesis of macrolactin \\
\hline RBAM_018420 & fenE & Fengycin synthetase FenE, synthesis of fengycin \\
\hline RBAM_003680 & srfaC & Surfactin synthetase C SrfAC, synthesis of surfactin \\
\hline RBAM_003690 & srfaD & Surfactin synthetase D SrfAD, synthesis of surfactin \\
\hline \multicolumn{3}{|c|}{ Secretome enhanced in the presence of root exudate (Kierul, unpublished) } \\
\hline RBAM_032500 & fliD & Flagellin HAP2; involved in elicitation of plant basal defense, motility \\
\hline RBAM_032510 & hag & Flagellin; involved in elicitation of plant basal defense, motility and chemotaxis \\
\hline RBAM_026420 & $\operatorname{tpx}$ & Thiol peroxidase, resistance against oxidative stress \\
\hline RBAM_020470 & ponA & Bifunctional glucosyltransferase/transpeptidase, membrane protein \\
\hline RBAM_011380 & appA & Oligopeptide $A B C$ transporter (binding protein) \\
\hline RBAM_011430 & oppA & Oligopeptide $A B C$ transporter (binding protein) \\
\hline RBAM_023290 & psts & Phosphate $A B C$ transporter (binding protein) \\
\hline RBAM_022520 & yqiG & NADH-dependent flavin oxidoreductase \\
\hline RBAM_026160 & $m d h$ & Malate dehydrogenase Mdh, carbon core metabolism, TCA cycle \\
\hline RBAM_033170 & alss & Acetolactate synthase, synthesis of 2,3-butanediol, plant growth promotion, elicitation of plant ISR \\
\hline RBAM_025870 & $a b n A$ & Arabinan-endo 1,5-alpha-L-arabinase, utilization of arabinan \\
\hline RBAM_017540 & chbA & Putative chitin-binding protein, utilization of chitin/chitosan \\
\hline RBAM_018140 & xynC & Endo-1,4-beta-xylanase, utilization of xylan \\
\hline RBAM_035930 & gmuG & Endo-beta-1,4-mannanase, utilization of glucomannan \\
\hline
\end{tabular}

Data were compiled from Idris et al. (2007), Fan et al. [20], Budiharjo et al. [11], and Kierul et al. (in preparation). Genes involved in plant-bacteria interactions in FZB42. The genes detected in both transcriptome and secretome analysis are in bold.

the microscopic sample, and (4) plating of the 10-1 to 10-5 diluted samples onto lactose (0.1\%) minimal agar plates with $0.1 \%$ azure dye-stained hydroxyl ethyl cellulose
(AZCL HE). Colonies hydrolyzing AZCL and displaying the typical morphology of FZB42 (rough, flat, dendritic, translucent, white) were analyzed after 3 days for presence 
Table 3 Characterization of isolates from soil samples obtained 5 months after application of FZB42 to Antirrhinum majus cultures in October 2009, Chengong County, Kunming

\begin{tabular}{|c|c|c|c|c|c|c|}
\hline Strain & Lactose MM & Cellulose & RM (785 bp) & Nrs (839 bp) & Pzn (821 bp) & Morphology (nutrient agar) \\
\hline FZB42 & + & + & + & + & + & Rough, flat, dendritic, translucent, white \\
\hline KM 1-1 & + & + & + & + & + & As FZB42 \\
\hline KM 1-2 & + & + & + & + & + & As FZB42 \\
\hline KM 1-3 & + & + & + & + & + & As FZB42 \\
\hline $\mathrm{KM} 2 \mathrm{~A}$ & + & + & + & + & + & As FZB42 \\
\hline $\mathrm{KM} 2 \mathrm{~B}$ & + & + & + & + & + & As FZB42 \\
\hline KM3 & + & + & + & + & + & As FZB42 \\
\hline KM 4-1 & + & + & + & + & + & As FZB42 \\
\hline KM 4-2 & + & + & + & + & + & As FZB42 \\
\hline KM 5-1 & + & + & + & + & + & As FZB42 \\
\hline KM 5-2 & + & + & + & + & + & As FZB42 \\
\hline KM 6-1 & + & + & + & + & + & As FZB42 \\
\hline KM 6-2 & + & + & + & + & + & As FZB42 \\
\hline $\mathrm{DSM}^{\top}$ & + & - & - & - & - & Rough, white \\
\hline B. subtilis DSM10 ${ }^{\top}$ & - & + & - & - & - & Soft, cream \\
\hline
\end{tabular}

The colonies were analyzed after 3 days for presence of a unique 785-bp DNA fragment by PCR using primers PRBrm5215 and PRBrm6000 (see text). In addition, two other primer pairs PRBnrs3104 5'...tggagaaatatcactgaacaatgc and PRBnrs3943 $5^{\prime}$....acgtttagtttcagttctttcacc for detection of the $n r s$ gene cluster and PRBptn6179 5'gatagaagtattagcctggaagca and PRBptn7000 5'...tggaggaggtaacaattatgactc for detection of the pzn (plantazolicin) gene cluster were used. Annealing temperature of $55^{\circ} \mathrm{C}$ was generally used in PCR.

of an unique 785-bp DNA fragment by PCR using primers PRBrm5215 $5{ }^{\prime}$...TGATGGAGTAAATAATAAGGCTGG and PRBrm6000 5'... AATACATCTAAAGTTGCATC CACC. Amplification with two other primer pairs (Table 3) indicating presence of the $n r s$ and $p z n$ gene clusters was also found useful for examining the obtained colonies by either colony PCR or using isolated chromosomal DNA as template. The isolated colonies were examined for their ability to colonize plant roots using microbial standard techniques [7], and the genomes of the selected clones were sequenced to detect mutations possibly responsible for their improved capability to colonize plant roots. We propagated the most promising clones to obtain samples used in greenhouse and field trials. By using that approach, it was possible to obtain isolates with improved ability to colonize plant roots without engineering their genomes. Field trials to demonstrate enhanced positive response by the plant are underway.

In the following, we describe in more detail, a possibility to obtain more efficient strains by applying genetic engineering techniques in the plant growth-promoting strain FZB42. This work has been performed in the laboratory of Xuewen Gao, Nanjing Agriculture University, China. We have to acknowledge that at present, use of such engineered PGPR strains under field conditions is refused by the public, at least in Europe. However, in light of a steadily increasing world's population growing from 7 billion now to 8.3 billion in 2025 [29], innovative approaches for getting higher harvest yields without using increasing amounts of agrochemicals should not longer be excluded, given that their use is safe and without harmful consequences for human beings and nature. Careful environmental studies are a precondition before releasing genetic engineered bacteria into the environment.

\section{Case study: expression of the Harpin gene enhances biocontrol activity of FZB42}

The plant immune system has gained recognition as a major factor in the growth and development of plants and the resistance to disease, predation, and environmental stress. The hrp ('harp') genes encode type III secretory proteins enabling many phytopathogenic bacteria to elicit a hypersensitive response (HR) on nonhost or resistant host plants and induce pathogenesis on susceptible hosts. The HR is a rapid localized death of the host cells that occurs upon pathogen infection and, together with the expression of a complex array of defense-related genes, is a component of plant resistance. The plant genes create a cascade of effects which promote a systemic acquired resistance (SAR) throughout the plant. Beneficial effects on plant growth and health have been reported [30].

The hrp genes were first identified in Pseudomonas syringae pv. phaseolicola, a bean pathogen [31], and then in the plant pathogen Erwinia amylovora by the group of Steven Beer at Cornell University [32]. An optimized technology for producing the E. amylovora Harpin in a 
recombinant Escherichia coli strain was subsequently developed [33]. Today, Plant Health Care (PHC) promotes Harpin $_{\mathrm{a} \beta}$ as foliar applicant and seed treatment on the global crop market.

Xanthomonas oryzae pv. oryzicola, the cause of bacterial leaf streak in rice, possesses clusters of hrp genes that determine its ability to elicit a HR in non-host tobacco and pathogenicity in host rice [34,35]. The hpa1 gene of Xanthomonas oryzae pv. oryzae encodes a $13-\mathrm{kDa}$ glycine-rich protein with a composition similar to those of the harpins in Xanthomonas spp. and PopA in Rhizoctonia solanaceum [36]. The hpa $1_{\text {XooC }}$ gene was cloned and expressed in E. coli BL21 [37]. It is a member of the Harpin group of proteins, eliciting hypersensitive cell death in non-host plants, inducing disease and insect resistance in plants, and enhancing plant growth. Despite completely different sequence, its function was found very similar to that of the E. amylovora Harpin protein [38]. Transgenic tobacco plants expressing the $h p a 1_{\text {XоoC }}$ gene were constructed but were found unable to induce hypersensitive cell death (HCD) [39].
The $h p a G_{X o o C}$ gene had been cloned on an expression plasmid in B. subtilis OKB105, a derivative of B. subtilis 168 which is able to produce surfactin [40] and to colonize plant roots. Application experiments in tomato plants demonstrated that OKB105 expressing $\mathrm{HpaG}_{\text {XooC }}$ was improved in its biocontrol activity [41]. However, after 100 generations, the $\mathrm{HpaG}_{\mathrm{XooC}}$ expression plasmid pM43HF is unstable in B. subtilis, which does not allow the use of this system under large-scale conditions in practice [42]. In order to overcome this difficulty, the groups from Nanjing Agricultural University and Humboldt University decided to use the plant growth-promoting model strain FZB42 as a host for establishing a durable and efficient $\mathrm{HpaG}_{\mathrm{XooC}}$ expression system [43]. In order to avoid proteolytic destruction of the recombinant harpin gene product, we removed the two main extracellular proteases Apr and Npr from FZB42. Chromosomal integration of two hpa 1 genes cloned from $X$. oryzae under the control of the strong $\mathrm{P}_{43}$ promoter allowed stability and constitutive expression of the hpa1 gene product in FZB42. The experiment was described extensively in [43], but unfortunately in Chinese. Here, we present a short outline.

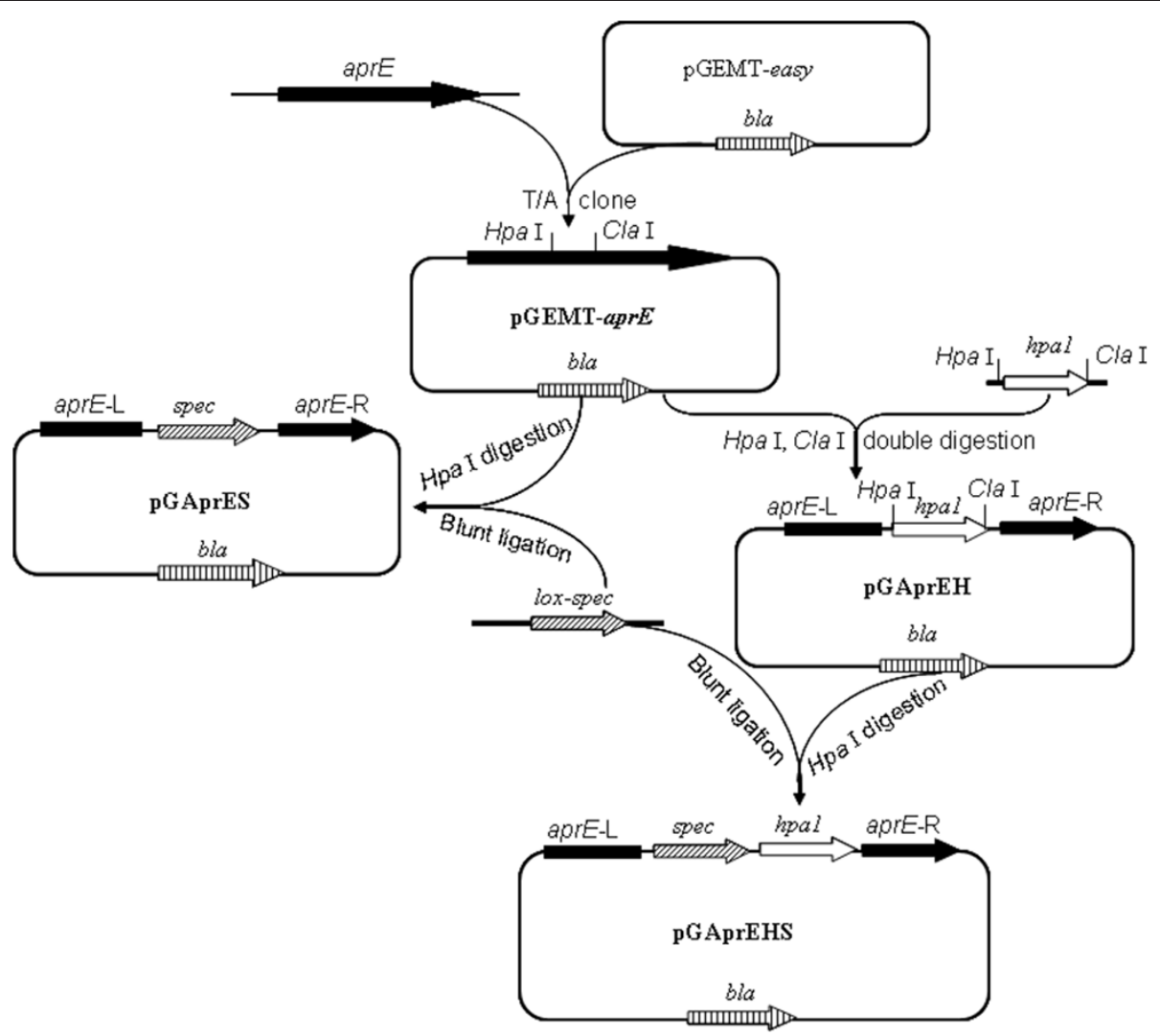

Figure 1 Construction of the Harpin expression vector pGAprEHS. The amplified partial FZB42 aprE gene sequence was cloned into pGEMT T/A vector resulting in PGEMT-aprE. Then, the gene encoding $\mathrm{HpaG}_{\mathrm{x}_{o o} \mathrm{C}}$ was inserted into the double-digested (Hpal and Clal) plasmid pGEMT-aprE resulting in pGAprEH. Finally, the antibiotic-resistance marker Spec was amplified from plasmid pIC333 and inserted into vector pGAprEH, yielding integration vector pGAprEHS. In addition, the aprE knockout vector pGAprES was obtained when the antibiotic cassette was inserted into plasmid pGEMT-aprE. 
Briefly, two recombinant Harpin protein integration vectors, pGAprEHS (Figure 1) and pUNprEKHS (Figure 2), were constructed. The two vectors contained the powerful $\mathrm{P}_{43}$ promoter and the $n p r B$ signal peptide, which were fused with the gene encoding $\mathrm{HpaG}_{\mathrm{XooC}}$. In addition, the vectors, which were unable to replicate freely in Bacillus cells, contained parts of the aprE and nprE sequences of FZB42, allowing their target-specific integration into the FZB42 chromosome. Transformation of pGAprEHS into competent cells of FZB42 resulted in the removal of the two main proteases, AprE and NprE, and yielding FZB42AN (Figure 3A). Subsequently, two copies of the hpa1 gene were inserted into the former protease gene sites in FZB42AN using plasmid pUNprEKHS. The resulting engineered strain FZBHarpin (Table 4) contained two copies of the hpal gene and the antibiotic marker fragments (lox-Km, lox-Spec, Cre-lox).

\section{Experimental methods}

The tobacco (Nicotiana tabacum cv. NC89) seeds were first soaked in FZB-derived strain suspensions with a final concentration of $1 \times 10^{8} \mathrm{CFU}$ for $12 \mathrm{~h}$ and then disinfested in a $15 \%(w / v)$ solution of sodium hypochlorite for $15 \mathrm{~min}$ and washed three times with sterilized distilled water. These seeds were sown onto square Petri dishes $\left(10 \mathrm{~cm}^{2}\right)$ containing solidified Murashige medium. Each treatment included five plates with ten seeds each, and the experiment was replicated three times. The petri dishes were incubated in an illuminated incubator (200 $\mu \mathrm{E} \mathrm{m} \mathrm{m}^{-2} \mathrm{~s}^{-1}$ at $25^{\circ} \mathrm{C}$ ) with a 16 -h day and 8-h night cycle. The root length was measured after 4 to 5 weeks.

FZB42, FZBAN, and FZBHarpin were cultivated in Landy medium at $30^{\circ}$ and $200 \mathrm{rpm}$. Bacterial cultures were taken after 24,48 , and $72 \mathrm{~h}$, respectively, and were infiltrated into the intercellular space of tobacco leaves (N. tabacum L. 'xanthi'). The Landy medium and the Harpin protein purified from E. coli $\left(50 \mathrm{ug} \cdot \mathrm{ml}^{-1}\right)$ served as the negative and positive controls, respectively. The development of the HR was registered after incubation for 24 to $36 \mathrm{~h}$ at room temperature.

The rice cultivar 'Fengyou 22' was used in this study. FZB-derived strains were shaken at $200 \mathrm{rpm}$ at $30^{\circ} \mathrm{C}$ for

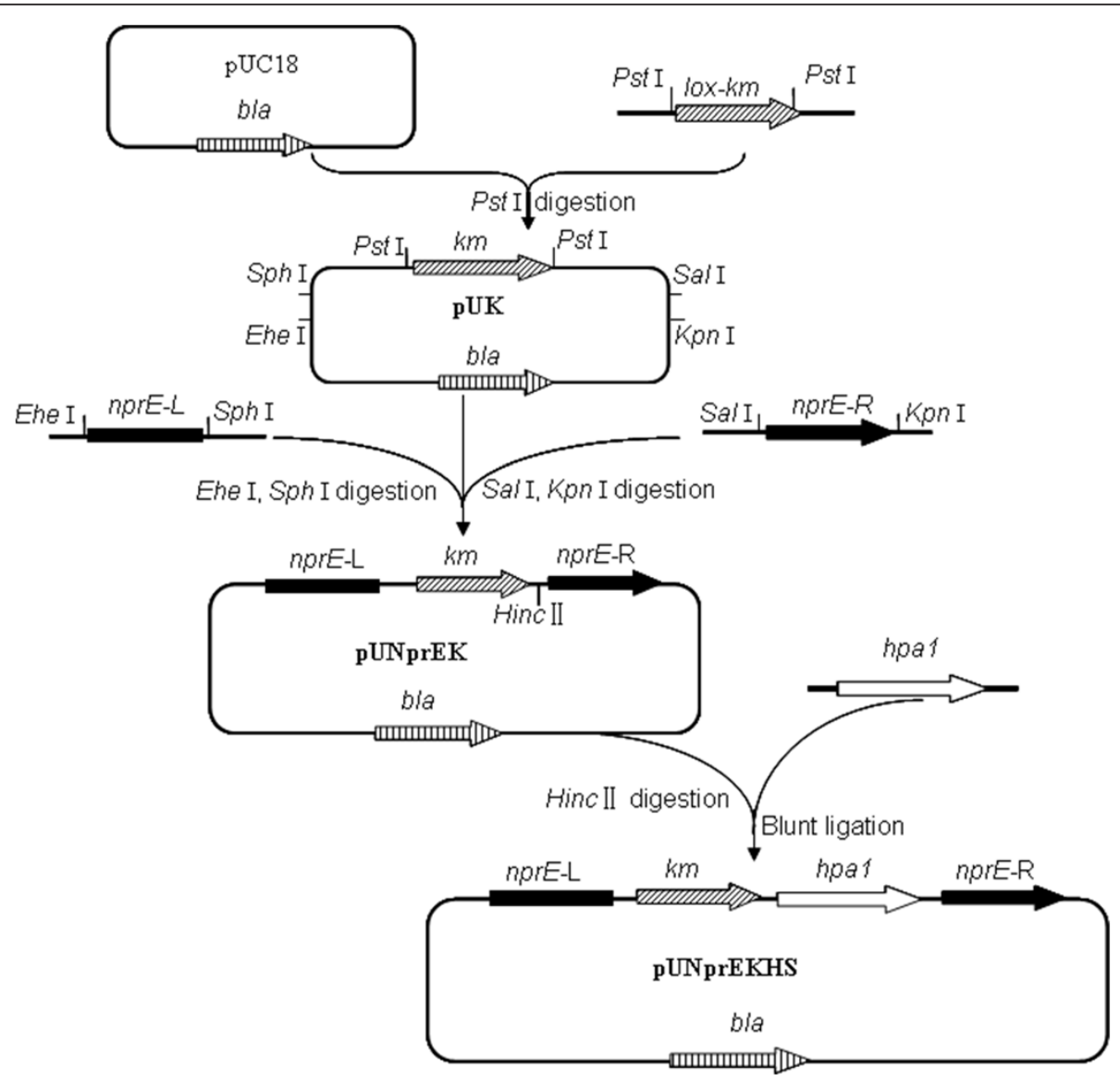

Figure 2 Construction of the Harpin expression vector pUNprEKHS. The resistance marker lox-Km was obtained from plasmid pBT2-arcA (Leibig et al. [45]) after Pstl digestion and subsequent cloning into pUC18. The resulting plasmid was named pUK. The upstream and downstream sequences of the nprE gene were inserted into plasmid pUK, yielding nprE knockout vector pUNprEK. The Harpin gene fused with the $\mathrm{P}_{43}$ promoter and the nprE signal peptide was inserted into the Hinc II site of pUNprEK, yielding pUNprEKHS. 


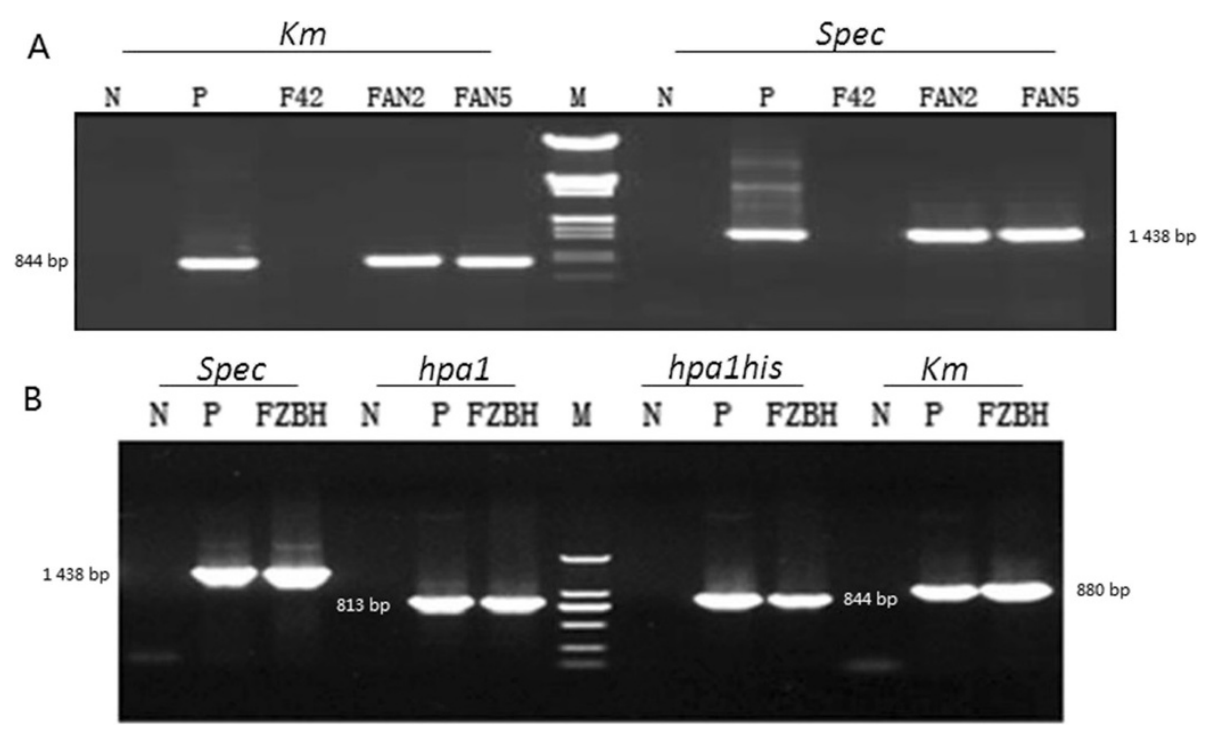

Figure 3 PCR analysis of FZBAN and FZBHarpin. (A) Validation of FZB42AN (FAN, DnprE DnprA, deficient in neutral and alkaline protease). Left: N, negative control (double distilled water); P, 844-bp fragment from the Km-containing plasmid; FAN 2 and FAN5, presence of the Km resistance cassette in two FZB42AN isolates. Right: $\mathrm{N}$, negative control (double distilled water); $\mathrm{P}, 1,438$-bp fragment from the Spec-containing plasmids; FAN 2 and FAN5, respectively, presence of the Spec resistance cassette in the two FZB42AN isolates. (B) Validation of FZBHarpin ( $F Z B H$, nprE::hpa1 nprA::hpa1). Lanes from left to right: presence of the spec resistance gene (1,438 bp) in FZB42Harpin, presence of the hpa 1 gene (813 bp) in FZB42Harpin, presence of the his-tagged hpal gene (844 bp) in FZB42Harpin, and presence of the km resistance gene (880 bp) in FZB42Harpin.

$72 \mathrm{~h}$. The culture was adjusted to about $1 \times 10^{8} \mathrm{CFU} \mathrm{ml} \mathrm{H}^{-1}$ with sterile distilled water for use. The rice seeds were surface-sterilized using sodium hypochlorite $(15 \%, v / v)$ for $15 \mathrm{~min}$, washed three times in sterile water, and allowed to germinate for 2 to 3 days at $25^{\circ} \mathrm{C}$. Then, the seeds were soaked in the Bacillus spore suspension at $25^{\circ} \mathrm{C}$ for $2 \mathrm{~h}$. The seeds were sown into sterile soil pots, containing a mixture of vermiculite and organic manure $(1: 1, w / w)$. Five plants are placed in each pot, and each treatment includes ten pots. These pots were cultivated in a greenhouse at $18^{\circ} \mathrm{C}$ to $30^{\circ} \mathrm{C}$. After 45 days, the $\mathrm{FZB}$ suspension was diluted to $10^{8} \mathrm{CFU} \mathrm{ml}^{-1}$ and used for spray treatment. After 1 day, the treated pots were inoculated with the bacterial leaf blight pathogen $X$. oryzae pv. oryzae POX99 (ca. $10^{9} \mathrm{CFU} \mathrm{ml}^{-1}$ ). Bacterial leaf blight symptoms were assessed 21 days after inoculation. The height of the plants was measured.

\section{Results and discussion}

Quantitative real time PCR (qPCR) revealed constitutive expression of the two Harpin genes in the transgenic FZBHarpin strain (Figure 4). Although the harpin gene products were not detected in the supernatant of FZBHarpin by SDS-PA gel electrophoresis, their effect on tobacco plants were clearly visible: $H R$ on tobacco was induced by supernatants taken from FZBHarpin cultures, demonstrating that biological active Harpin protein was secreted into the medium (Figure 5). Moreover, the plant growth-promoting effect of FZB42 was found to be increased in the FZB42Harpin derivative, as demonstrated by enhanced root growth. The average root length in FZB42Harpin was increased by $30 \%$ compared to the untreated control (Figure 6).

Greenhouse experiments demonstrated efficacy of FZBHarpin in biocontrolling rice bacterial blight. The control efficacy of FZB42Harpin was 51.9\%. In addition, a plant growth-promoting effect by FZB42Harpin exceeding that of FZB42 was also detected (Table 5). Before applying the recombinant FZB42Harpin strain in field trials, removal of the two resistance markers flanked by the Crelox recombinase recognition sites via site-directed recombination has to be performed.

\section{Outlook: how to improve acceptance for use of genetic engineered bacteria for enhancing crop yield?}

Today, application and release of genetic engineered bacteria directly in the environment is not accepted by the public, and governmental regulations are contradictory for use of such microorganisms in enhancing crop yield. One reason is the presence of resistance genes in transgenic strains, which have been introduced in the bacteria during the allelic replacement process, and methods avoiding use of such marker genes are therefore highly desirable. 
Table 4 Strains and plasmids used for constructing FZB42Harpin

\begin{tabular}{|c|c|c|}
\hline $\begin{array}{l}\text { Strains/ } \\
\text { plasmids }\end{array}$ & Description & $\begin{array}{l}\text { Reference or } \\
\text { source }\end{array}$ \\
\hline \multicolumn{3}{|l|}{ Plasmids } \\
\hline pUC18 & Cloning vector; lacZ $A p^{r}$ & Lab collection \\
\hline pGEMT-easy & T/A-clone site vector; lacZ; $A p^{r}$ & $\begin{array}{l}\text { Promega Corp. } \\
\text { Fitchburg, Wisconsin }\end{array}$ \\
\hline $\mathrm{pBT} 2-\operatorname{arcA}$ & Allelic replacement vector for Staphylococcus aureus containing a Km resistance cassette & Leibig et al. [45] \\
\hline $\mathrm{plC} 333$ & A vector carrying mini-Tn10 transposase gene for Bacillus subtilis, offer of Spec cassette & Laboratory stock \\
\hline pM43HF & Expression vector carrying hpal gene under the control of promoter p43 and the $n p r B$ signal peptide & Wu et al. [42] \\
\hline pGAprEHS & $\begin{array}{l}\text { pGEM-T carrying a 2.8-kb fragment containing aprE, a 1.4-kb fragment lox-Spec and a 0.8-kb fragment hpal; } \\
\text { Ap }^{r} \text {, Spec }{ }^{r}\end{array}$ & This study \\
\hline pGAprES & pGEM-T carrying a 2.8-kb fragment containing aprE, a 1.4-kb fragment lox-Spec; Ap', Spec ${ }^{r}$ & This study \\
\hline pUNprEKHS & pUC18 plasmid carrying a lox-Km cassette, $n p r E-L, n p r E-R$ fragment, hpa1-his fragment; $A p^{R}, K^{R}$ & This study \\
\hline pUNprEK & pUC18 plasmid carrying a lox-Km cassette, $n p r E-L$ fragment and $n p r E-R$ fragment; $\mathrm{Ap}^{R}, \mathrm{Km}^{R}$ & This study \\
\hline \multicolumn{3}{|l|}{ Strains } \\
\hline \multicolumn{3}{|l|}{ E. coli } \\
\hline Topo10 & $\begin{array}{l}\text { F-mcrA } \Delta(\text { mrr-hsdRMS-mcrBC } \varphi 80 \text { lacZ } \Delta M 15 \Delta \text { lacX74 nupG recA1 araD139 } \Delta \text { (ara-leu)7697 galE15 } \\
\left.\text { galK16 rpsL(Str }{ }^{\beta}\right) \text { endA1 } \lambda^{-}\end{array}$ & Invitrogen \\
\hline \multicolumn{3}{|c|}{ Bacillus amyloliquefaciens } \\
\hline FZB42 & Type strain for Bacillus amyloliquefaciens subsp. plantarum & $\begin{array}{l}\text { ABiTEP GmbH, } \\
\text { Berlin, Germany }\end{array}$ \\
\hline FZB42/AHS & FZB42 $\triangle a p r E \Delta n p r E::$ hpa1:: lox-Spec & This study \\
\hline FZBHarpin & 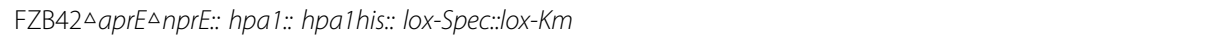 & This study \\
\hline FZBAN & 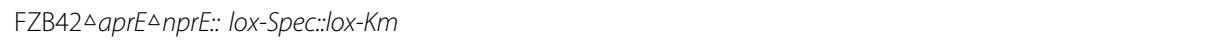 & This study \\
\hline \multicolumn{2}{|c|}{ Xanthomonas oryzae pv. oryzae POX99 } & This study \\
\hline
\end{tabular}

Today there are several methods for marker removal available. Wang et al. [44] developed a simple and efficient B. subtilis genome editing method in which targeted gene(s) could be inactivated by single-stranded PCR product(s) flanked by short homology regions, and in-frame deletion could be achieved by incubating the transformants at $42^{\circ} \mathrm{C}$. In this process, homologous recombination was promoted by the lambda beta protein synthesized under the control of promoter PRM in the lambda cI857 PRM-PR promoter system on a temperature-sensitive plasmid pWY121.

Alternatively, site-specific recombination systems are capable of eliminating antibiotic resistance markers, if they are flanked by recombinase recognition sites as it is the case in FZB42Harpin. In a previous study [45], a Cre-lox setting was established that allowed the efficient removal of resistance genes from the genomes of Staphylococcus carnosus and Staphylococcus aureus. Two cassettes conferring resistance to erythromycin or kanamycin were flanked with wild-type or mutant lox sites, respectively, and used to delete single genes and an entire operon. After transformation of the cells with a newly constructed cre expression plasmid, genomic

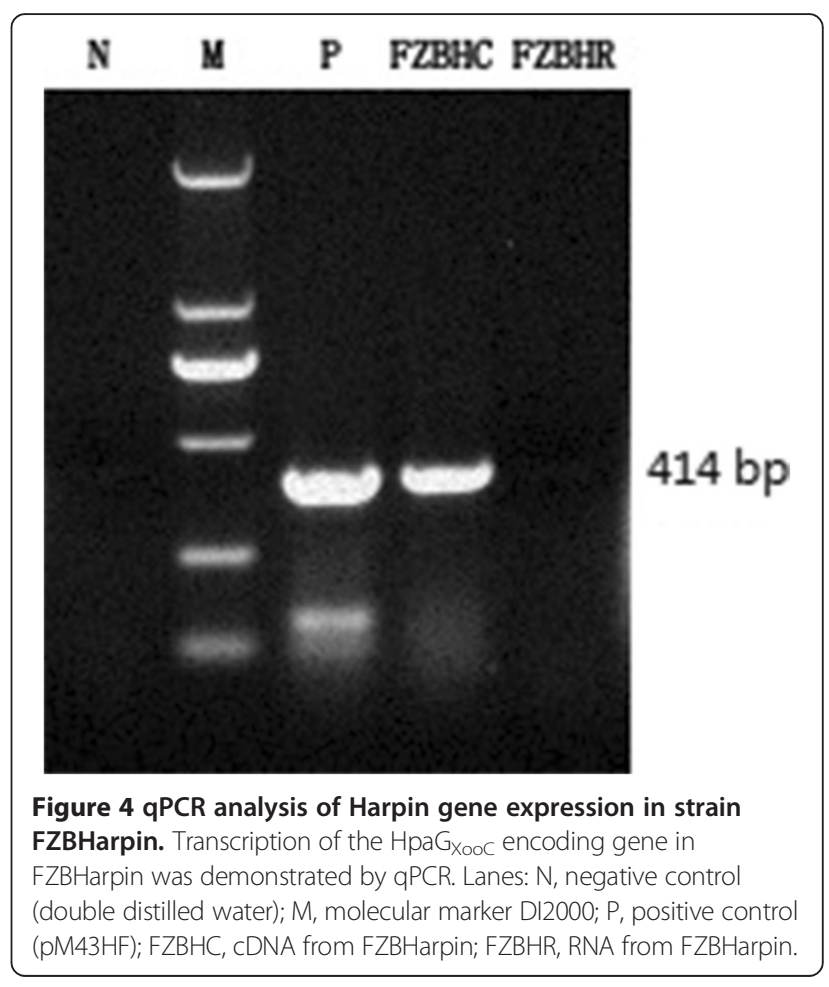




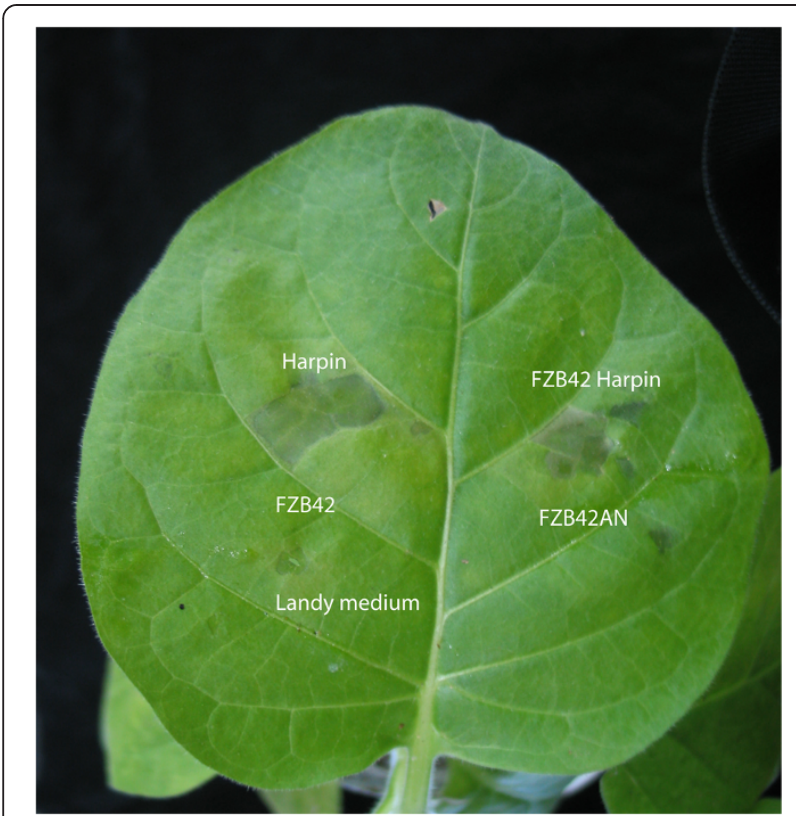

Figure 5 Hypersensitive response in tobacco elicited by FZBHarpin. The strains were cultivated in Landy medium, and the samples were taken after $72 \mathrm{~h}$. One hundred microliters of the supernatant and of recombinant $\mathrm{Hrp}_{\text {xooc }}\left(15 \mu \mathrm{g} \cdot \mathrm{ml}^{-1}\right)$ were applied onto tobacco leaf surfaces, and the hypersensitive response was checked after $24 \mathrm{~h}$.

eviction of the resistance genes was observed in approximately one out of ten candidates analyzed and subsequently verified by PCR. Due to its thermosensitive origin of replication, the plasmid can be eliminated at non-permissive temperatures, and markerless deletion mutants can be obtained. Before applying the engineered FZB42Harpin under non-containment conditions, we have to perform marker removal by one of the methods described above.

Of course, marker removal is not the only precondition for improved acceptance of genetically engineered strains when released into the environment. As stated above, careful case studies demonstrating that no harmful effects caused by genetic engineered strains are urgently needed. In applying genetic engineered plant growth-promoting bacteria, we have to distinguish two different levels:

(1)Engineered strains without foreign genes but containing useful mutations in genes affecting the beneficial effect of the bacterium in terms of plant growth promotion and biocontrol of pathogens. Given that no resistance marker has been introduced, it might be unimportant whether the useful mutation has been introduced by a targeted allele exchange or has been evolved after applying a natural selection procedure. We believe that such strains will be accepted in the future when their improved action has been convincingly demonstrated.

(2) Engineered strains containing genes from bacteria. Such bacteria will be considered as 'recombinant' , also when the donor bacteria occur in the same natural environment. This was the case in the example described here. Ironically, the harpin gene isolated from a pathogen bacterium was shown to act beneficial when cloned and expressed in FZB42. However, long-term environmental studies are necessary to demonstrate that such recombinant bacteria do not harm the environment by novel recombination events with other microorganisms occurring in the same environment.

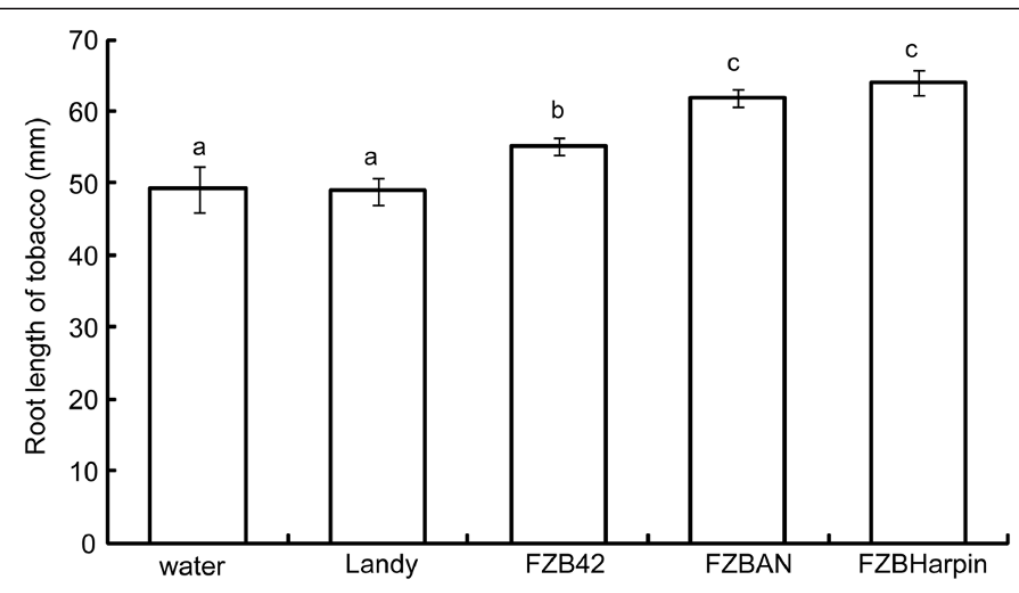

Figure 6 Promotion of root growth of tobacco plants grown in MS medium by FZB42Harpin. The lengths of the roots were determined as follows: control (water) 49.25 mm ( \pm 3.25$)$, control (Landy medium) 48.95 mm ( \pm 1.92$)$, FZB42 55.17 mm ( \pm 1.12$)$, FZBAN $(\Delta a p r, \Delta n p r) 61.79$ mm $( \pm 1.23)$, and FZBHarpin ( $\Delta a p r, \Delta n p r, 2 x$ hrp xood $64.05 \mathrm{~mm}( \pm 1.81)$. 


\section{Table 5 The biocontrol efficacy (rice bacterial blight) and plant growth promotion by FZB42, FZB42AN, and FZB42Harpin}

\begin{tabular}{llll}
\hline Strain & Disease index (\%) & Control efficacy (\%) & Plant height (cm) \\
\hline- & $44.25 \pm 2.82 \mathrm{a}$ & - & $71.75 \pm 3.54 \mathrm{c}$ \\
FZB42 & $36.57 \pm 1.73 \mathrm{~b}$ & 17.4 & $75.92 \pm 1.88 \mathrm{~b}$ \\
FZBAN & $28.97 \pm 2.01 \mathrm{C}$ & 34.5 & $80.33 \pm 1.53 \mathrm{a}$ \\
FZBHarpin & $21.26 \pm 2.73 \mathrm{~d}$ & 51.9 & $82.58 \pm 0.80 \mathrm{a}$ \\
\hline
\end{tabular}

Test was performed with tobacco plants. Groups designated as a, b, c are significantly different.

\section{Conclusions}

Biologicals prepared from beneficial microbes are useful and environmental-friendly tools for developing a sustainable and efficient agriculture. In this context, genomic analysis and genetic engineering of promising beneficial microbes are helpful for obtaining improved bioformulations. This strategy should enable us to save considerable amounts of agrochemicals, especially chemical fertilizers, and chemical pesticides.

\section{Competing interests}

The authors declare that they have no competing interests.

\section{Authors' contributions}

JQQ carried out the molecular genetic studies and application experiments with FZB42Harpin and helped to draft the manuscript. HJW and RH carried out the molecular genetic studies and application experiments with FZB42Harpin. XWG conceived of the study, and participated in its design and coordination and helped to draft the manuscript. RB designed the experiments and wrote the manunuscript. All authors read and approved the final manuscript.

\section{Authors' information}

JQQ is scientific coworker of Jiangsu Academy of Agricultural Sciences, Nanjing. HJW and RH are graduate students in the laboratory of XWG, Nanjing Agriculture University, Nanjing. RB is Prof. em. of Humboldt University Berlin and Director of Research at ABiTEP GmbH Berlin.

\section{Acknowledgements}

The work of X. Gao was supported by grants from the National High-Tech R\&D Program of China (2012AA101504), the Special Fund for Agro-Scientific Research in the Public Interest (20130315), the National Natural Science Foundation of China (31471811), and the Doctoral Fund of Ministry of Education of China (20100097120011). R.B. wishes to thank for the support given by the European's Seventh Framework Programme (FP/2007-2013) under Grant Agreement no. 312117.

\section{Author details \\ ${ }^{1}$ College of Plant Protection, Nanjing Agricultural University, Key Laboratory of Monitoring and Management of Crop Disease and Pest Insects, Ministry of Agriculture, Nanjing 210095, China. ${ }^{2}$ Institute of Plant Protection, Jiangsu Academy of Agricultural Sciences, Nanjing 210014, China. Institute of Biology/Bacterial Genetics, Humboldt University, Berlin, Germany. ${ }^{4}$ ABiTEP $\mathrm{GmbH}$, Berlin, Germany.}

Received: 6 April 2014 Accepted: 9 August 2014

Published online: 20 September 2014

\section{References}

1. Borriss R (2011) Use of plant-associated Bacillus strains as biofertilizers and biocontrol agents. In: Maheshwari DK (ed) Bacteria in agrobiology: plant growth responses. Springer Heidelberg, Dordrecht, London, New York, pp 41-76

2. Borriss R, Chen XH, Rueckert C, Blom J, Becker A, Baumgarth B, Fan B, Pukall R, Schumann P, Sproer C, Junge H, Vater J, Pühler A, Klenk HP (2011)
Relationship of Bacillus amyloliquefaciens clades associated with strains DSM $7^{\top}$ and Bacillus amyloliquefaciens subsp. plantarum subsp. nov. based on their discriminating complete genome sequences. Int J Syst Evol Microbiol 61:1786-1801

3. Krebs B, Hoding B, Kubart S, Workie MA, Junge $H$, Schmiedeknecht G, Grosch R, Bochow H, Hevesi M (1998) Use of Bacillus subtilis as biocontrol agent I. Activities and characterization of Bacillus subtilis strains. Z Pflanzenk Pflanzen 105:181-197

4. Chen XH, Koumoutsi A, Scholz R, Eisenreich A, Schneider K, Heinemeyer I, Morgenstern B, Voss B, Hess WR, Reva O, Junge $H$, Voigt B, Jungblut PR, Vater J, Süssmuth R, Liesegang H, Strittmatter A, Gottschalk G, Borriss R (2007) Comparative analysis of the complete genome sequence of the plant growth-promoting bacterium Bacillus amyloliquefaciens FZB42. Nat Biotechnol 25:1007-1014

5. Kenrick P, Crane PR (1997) The origin and early evolution of plants on land Nature 389:33-39

6. Hirsch PR, Miller AJ, Dennis PG (2013) Do root exudates exert more influence on rhizosphere bacterial community structure than other rhizodeposits? In: de Bruyn FJ (ed) Molecular microbial ecology of the rhizosphere. Wiley, Hoboken. vol. 1 pp 229-242

7. Chowdhury SP, Dietel K, Rändler M, Schmid M, Junge H, Borriss R, Hartmann A, Grosch R (2013) Effects of Bacillus amyloliquefaciens FZB42 on lettuce growth and health under pathogen pressure and its impact on the rhizosphere community. PLoS One 8(7):e68818

8. Fan B, Chen XH, Budiharjo A, Bleiss W, Vater J, Borriss R (2011) Efficient colonization of plant roots by the plant growth promoting bacterium Bacillus amyloliquefaciens FZB42, engineered to express green fluorescent protein. J Biotechnol 151:303-311

9. Dietel K, Beator B, Budiharjo A, Fan B, Borriss R (2013) Bacterial traits involved in colonization of Arabidopsis thaliana roots by Bacillus amyloliquefaciens FZB42. Plant Pathol J 29:59-66

10. Fan B, Borriss R, Bleiss W, Wu XQ (2012) Gram-positive rhizobacterium Bacillus amyloliquefaciens FZB42 colonizes three types of plants in different patterns. J Microbiol 50:38-44

11. Budiharjo A, Chowdhury SP, Dietel K, Beator B, Dolgova O, Fan B, Bleiss W, Ziegler J, Schmid M, Hartmann A, Borriss R (2014) Transposon mutagenesis of the plant-associated Bacillus amyloliquefaciens ssp. plantarum FZB42 revealed that the $n f r A$ and $R B A M 17410$ genes are involved in plant-microbe interactions. PLoS One 9(5):e98267

12. Chen XH, Koumoutsi A, Scholz R, Borriss R (2009) More than anticipated production of antibiotics and other secondary metabolites by FZB42. J Mol Microbiol Biotechnol 16:14-24

13. Rueckert C, Blom J, Chen XH, Reva O, Borriss R (2011) Genome sequence of Bacillus amyloliquefaciens type strain DSM7 ${ }^{\top}$ reveals differences to plantassociated Bacillus amyloliquefaciens FZB42. J Biotechnol 155:78-85

14. Chen XH, Vater J, Piel J, Franke P, Scholz R, Schneider K, Koumoutsi A, Hitzeroth G, Grammel N, Strittmatter AW, Gottschalk G, Sussmuth RD, Borriss $R$ (2006) Structural and functional characterization of three polyketide synthase gene clusters in Bacillus amyloliquefaciens FZB 42. J Bacteriol 188:4024-4036

15. Schneider K, Chen XH, Vater J, Franke P, Nicholson G, Borriss R, Süssmuth RD (2007) Macrolactin is the polyketide biosynthesis product of the pks2 cluster of Bacillus amyloliquefaciens FZB42. J Nat Prod 70:1417-1423

16. Borriss R (2013) Comparative analysis of the complete genome sequence of the plant growth-promoting bacterium Bacillus amyloliquefaciens FZB42. In: de Brujn FJ (ed) Molecular microbial ecology of the rhizosphere. Wiley, Hoboken. vol. 2, pp. 883-898

17. He P, Hao K, Blom J, Rueckert C, Vater J, Mao Z, Wu Y, Hou M, He P, He Y, Borriss R (2012) Genome sequence of the plant growth promoting strain Bacillus amyloliquefaciens subsp. plantarum B9601-Y2 and expression of mersacidin and other secondary metabolites. J Biotechnol 164:281-291

18. Scholz R, Molohon KJ, Nachtigall J, Vater J, Markley AL, Süssmuth RD, Mitchell DA, Borriss R (2010) Plantazolicin, a novel microcin B17/streptolysin S-like natural product from Bacillus amyloliquefaciens FZB42. J Bacteriol 193:215-224

19. Scholz R, Vater J, Budiharjo A, Wang Z, He Y, Dietel K, Schwecke T, Herfort S, Lasch P, Borriss R (2014) Amylocyclicin, a novel circular bacteriocin produced by Bacillus amyloliquefaciens FZB42. J Bacteriol 196:1842-52

20. Fan B, Carvalhais LC, Fedoseyenko D, von Wiren N, Borriss R (2012) Transcriptomic profiling of Bacillus amyloliquefaciens FZB42 in response to maize root exudates. BMC Microbiol 12:116 
21. Carvalhais LC, Dennis PG, Fan B, Fedoseyenko D, Kierul K, Becker A, von Wiren N, Borriss R (2013) Linking plant nutritional status to plant-microbe interactions. PLoS One 8(7):e68555. doi:10.1371/journal.pone.0068555

22. Lugtenberg BJJ, Dekkers L, Bloemberg GV (2001) Molecular determinants of rhizosphere colonization by Pseudomonas. Annu Rev Phytopathol 39:461-490

23. Weng J, Wang Y, Li J, Shen Q, Zhang R (2013) Enhanced root colonization and biocontrol activity of Bacillus amyloliquefaciens SQR9 by abrB gene disruption. Appl Microbiol Biotechnol 97:8823-8830

24. Idris ES, Iglesias DJ, Talon M, Borriss R (2007). Tryptophan-dependent production of indole-3-acetic acid (IAA) affects level of plant growth promotion by Bacillus amyloliquefaciens FZB42. Mol Plant-Microbe Interact 20:619-626.

25. Koumoutsi A, Chen XH, Vater J, Borriss R (2007) DegU and YczE positively regulate the synthesis of bacillomycin $D$ by Bacillus amyloliquefaciens strain FZB42. Appl Environ Microbiol 73:6953-6964

26. Mariappan A, Makarewicz O, Chen XH, Borriss R (2012) Two-component response regulator DegU controls the expression of bacilysin in plant-growth-promoting bacterium Bacillus amyloliquefaciens FZB42. J Mol Microbiol Biotechnol 22:114-125

27. Borriss R, Junge H, Gao XW, Wang Q, He Y (2010) Experiences in applying Bacillus-based biocontrol agents in Chinese agriculture. In: Conference Proceedings of the IOBCMPRS Working Group "Biological control of fungal and bacterial plant pathogens"; Graz, Austria 06/2010.

28. Bais HP, Fall R, Vivanco JM (2004) Biocontrol of Bacillus subtilis against infection of Arabidopsis roots by Pseudomonas syringae is facilitated by biofilm formation and surfactin production. Plant Physiol 134:307-319

29. Lugtenberg BJJ, Malfanova N, Kamilova F, Berg G (2013) Plant growth promotion by microbes. In: de Brujn FJ (ed) Molecular microbial ecology of the rhizosphere. Wiley, Hoboken. vol. 2, pp. 561-573

30. Alfano JR, Collmer A (2004) Type 3 secretion system effector proteins: double agents in bacterial disease and plant defense. Annu Rev Phytopathol 42:385-414

31. Lindgren PB, Peet RC, Panopoulos NJ (1986) Gene cluster of Pseudomonas syringae pv phaseolicola controls pathogenicity on bean plants and hypersensitivity on nonhost plants. J Bacteriol 168:512-522

32. Wei ZM, Laby RJ, Zumoff CH, Bauer DW, He SY, Collmer A, Beer SV (1992) Harpin, elicitor of the hypersensitive response produced by the plant pathogen Erwinia amylovora. Science 257:85-88

33. Baker CJ, Orlandi EW, Mock NM (1993) Harpin an elicitor of the hypersensitive response in tobacco caused by Erwinia amylovora elicits active oxygen production in suspension cells. Plant Physiol 102:1341-1344

34. Zhu WG, Magbanua MM, White FF (2000) Identification of two novel hrp-associated genes in the hrp gene cluster of Xanthomonas oryzae pv. oryzae. J Bacteriol 182:1844-1853

35. Zou LF, Wang XP, Xiang Y, Zhang B, Li YR, Xiao YL, Wang JS, Walmsley AR, Chen GY (2006) Elucidation of the hrp clusters of Xanthomonas oryzae pv. oryzicola that control the hypersensitive response in nonhost tobacco and pathogenicity in susceptible host rice. Appl Environ Microbiol 72:6212-6224

36. Zhou L, Chen G, Wu X, Wang J (2005) Cloning and sequence analysis of diverse members of avrBs3/PthA family of Xanthomonas oryzae pv. oryzicola. Sci Agric Sin 38:929-935

37. Li P, Lu XZ, Shao M, Long JY, Wang JS (2004) Genetic diversity of harpins from Xanthomonas oryzae and their activity to induce hypersensitive response and disease resistance in tobacco. Sci China C Life Sci 47:461-469

38. Liu FQ, Liu HX, Jia Q, Wu XJ, Guo S, Zhang J, Song F, Dong HS (2006) The internal glycine-rich motif and cysteine suppress several effects of the $\mathrm{HpaG}$ (XooC) protein in plants. Phytopathology 96:1052-1059

39. Peng JL, Bao ZL, Ren HY, Wang JS, Dong HS (2004) Expression of harpinXoo in transgenic tobacco induces pathogen defense in the absence of hypersensitive cell death. Phytopathology 94:1048-1055

40. Nakano MM, Marahiel MA, Zuber P (1988) Identification of a genetic locus required for biosynthesis of the lipopeptide antibiotic surfactin in Bacillus subtilis. J Bacteriol 170:5662-5668

41. Gao S, Wu H, Wang W, Yang Y, Xie S, Xie Y, Gao X (2013) Efficient colonization and harpins mediated enhancement in growth and biocontrol of wilt disease in tomato by Bacillus subtilis. Lett Appl Microbiol 57:526-533

42. Wu HJ, Wang S, Qiao JQ, Liu J, Zhan J, Gao XW (2008) Expression of $\mathrm{HpaG}_{\text {Xooc }}$ protein in Bacillus subtilis and its biological functions. J Microbiol Biotechnol 19:194-203
43. Qiao J, Wu HJ, Huo R, Borriss R, Gao XW (2013) Construction of Harpin expression engineering strain FZBHarpin and evaluation of its biocontrol activity. J Nanjing Agric Univ 36:37-44

44. Wang Y, Weng J, Waseem R, Yin X, Zhang R, Shen Q (2012) Bacillus subtilis genome editing using ssDNA with short homology regions. Nucleic Acids Res 40:12e91

45. Leibig M, Krismer B, Kolb M, Friede A, Götz F, Bertram R (2008) Marker removal in Staphylococci via Cre recombinase and different lox sites. Appl Environ Microbiol 2008(74):1316-1323

doi:10.1186/s40538-014-0012-2

Cite this article as: Qiao et al:: Stimulation of plant growth and biocontrol by Bacillus amyloliquefaciens subsp. plantarum FZB42 engineered for improved action. Chemical and Biological Technologies in Agriculture 2014 1:12.

\section{Submit your manuscript to a SpringerOpen ${ }^{\odot}$ journal and benefit from:}

- Convenient online submission

- Rigorous peer review

- Immediate publication on acceptance

- Open access: articles freely available online

- High visibility within the field

- Retaining the copyright to your article

Submit your next manuscript at $>$ springeropen.com 